\title{
COMUNICAÇÃO
}

\section{CUSTO DE PRODUÇÃO E RENTABILIDADE DAS CULTURAS DE ALFACE, RABANETE, RÚCULA E REPOLHO EM CULTIVO SOLTEIRO E CONSORCIADAS COM PIMENTÃO}

\author{
Production cost and profitability of lettuce, radish, arugula and cabbage sole \\ crop and intercropped with sweet pepper
}

\author{
Bráulio Luciano Alves Rezende ${ }^{1}$, Aurélio Paes Barros Júnior ${ }^{1}$, Arthur Bernardes Cecílio Filho², \\ Diego Resende Queiros Pôrto ${ }^{3}$, Maria Inez Espagnoli Geraldo Martins ${ }^{4}$
}

\begin{abstract}
RESUMO
Realizou-se, o trabalho na UNESP, Jaboticabal, SP, com o objetivo de avaliar a rentabilidade das culturas de alface, rabanete, rúcula e repolho, em cultivo solteiro e consorciadas com pimentão. A determinação dos custos de produção das culturas em cultivo solteiro e em consórcio foi realizada com base na metodologia do custo operacional total (COT), com valores referentes a março de 2005. Para o cálculo da receita bruta, considerou-se o preço do setor atacadista, CEAGESP, no mês de março de 2005. Os COT das culturas de repolho, rúcula, alface e rabanete, quando consorciadas com pimentão, tiveram redução de $34,0 \%, 24,7 \%, 21,3 \%$ e $20,8 \%$ em relação aos seus respectivos cultivos solteiros. As culturas de alface e rabanete consorciadas com pimentão apresentaram aumento na receita líquida em $49,6 \%$ e $13,9 \%$, respectivamente, quando comparadas com seus cultivos solteiros. A maior rentabilidade foi obtida em consórcio de pimentão com alface. A taxa de retorno e índice de lucratividade dos consórcios foram superiores aos observados nas monoculturas.
\end{abstract}

Termos para indexação: Lactuca sativa, Eruca sativa, Brassica oleracea var. capitata, Capsicum annuum, Raphanus sativus, Viabilidade econômica.

\section{ABSTRACT}

This work was carried out at UNESP, in Jaboticabal, SP, with the aim of evaluating the production cost and profitability of lettuce, radish, arugula and cabbage sole crop and intercropped with sweet pepper. The determination of the production cost was accomplished with base on the methodology of the total operational cost (TOC), in March of 2005. For the calculation of the gross revenue, the price of the wholesale sector, CEAGESP, applied in March 2005, was considered. The TOC of the cultures cabbage, arugula, lettuce and radish when intercropped with sweet pepper had a reduction of $34.0 \%, 24.7 \%, 21.3 \%$ and $20.8 \%$, when compared to their respective single cultivation. The cultures of lettuce and radish intercropped with sweet pepper had net revenue increase of $49.6 \%$ and $13.9 \%$, respectively, when compared to their single cultivation. The largest profitability was obtained when sweet pepper was intercropped with lettuce. The return rate and the profitability index of the intercropping were higher than those of the single cultivation.

Index terms: Lactuca sativa, Eruca sativa, Brassica oleracea var. capitata, Capsicum annuum, Raphanus sativus, Economic viability.

(Recebido em 12 de abril de 2007 e aprovado em 18 de janeiro de 2008)

Uma das práticas que vem sendo usada com sucesso na olericultura é a consorciação de culturas. Principalmente, quando realizada em moldes agroecológicos, tem geralmente apresentado vantagens nos aspectos produtivo, nutricional, econômico e ambiental (DAVIS \& WOOLLEY, 1993).

Uma das principais razões pelas quais os agricultores, em diversas regiões do mundo, preferem o sistema consorciado é que, freqüentemente, obtêmse maiores produtividades do que a monocultura, por unidade de área cultivada (BARROS JÚNIOR, 2004). Esse aumento da eficiência do uso da terra é particularmente importante em pequenas propriedades, que são responsáveis, segundo Camargo Filho \& Mazzei (2001), por $75 \%$ da produção brasileira de hortaliças.

\footnotetext{
'Engenheiros Agrônomos, Mestres em Produção Vegetal - Departamento de Produção Vegetal - Faculdade de Ciências Agrárias e Veterinárias/FCAV Universidade Estadual Paulista/UNESP - Via de Acesso Professor Donato Castellane, s/n - 14884-900 - Jaboticabal, SP - blrezende@gmail.com; aureliojr02@yahoo.com.br

Engenheiro Agrônomo, Doutor, Professor - Departamento de Produção Vegetal - Faculdade de Ciências Agrárias e Veterinárias/FCAV - Universidade Estadual Paulista/UNESP - Via de Acesso Professor Donato Castellane, s/n - 14884-900 - Jaboticabal, SP - rutra@fcav.unesp.br - Bolsista do CNPq ${ }^{3}$ Engenheiro Agrônomo, Mestre em Produção Vegetal - Setor de Agricultura I-Olericultura - Escola Agrotécnica Federal de Sousa/EAFS - Rua Presidente Tancredo Neves, s/n - Jardim Sorrilândia - 58800-970 - Sousa, PB - portodrq@hotmail.com

${ }^{4}$ Médica Veterinária, Doutora, Professora - Departamento de Economia Rural - Departamento de Produção Vegetal - Faculdade de Ciências Agrárias e Veterinárias/FCAV - Universidade Estadual Paulista/UNESP - Via de Acesso Professor Donato Castellane, s/n - 14884-900 - Jaboticabal, SP minezesp@fcav.unesp.br
} 
Outras vantagens da consorciação sobre a monocultura são: otimização do uso do solo; água e luz (CECÍLIO FILHO \& MAY, 2002; WILLEY, 1979); melhor aproveitamento de fertilizantes e defensivos agrícolas (HORWITH, 1985); melhor cobertura do solo com, conseqüente, menor erosão (BEETS, 1975; ZAFFARONI, 1987) e maior diversidade biológica (FRANCIS, 1986).

Entretanto, para recomendar o cultivo consorciado de hortaliças, além da avaliação quantitativa (produtividade), realizada pelo índice de eficiência do uso da área, há que estudar a viabilidade econômica, na qual contempla-se a qualidade das hortaliças produzidas e o preço (sazonalidade). O estudo da eficiência econômica é essencial à determinação do custo de produção de um processo produtivo, que tem como uma das finalidades servir para a análise de rentabilidade dos recursos empregados (REIS et al., 1999).

Analisando o valor agroeconômico do consórcio alface-do grupo lisa-e cenoura cv. Brasília, em dois sistemas de cultivos em faixas em canteiros (três fileiras de cenoura alternadas com três fileiras de alface e quatro fileiras de cenoura alternadas com quatro fileiras de alface), Andrade (2002) verificou que o consórcio cenoura mais alface cv. Verdinha, em faixas com quatro fileiras, em canteiros foi o mais viável agroeconomicamente, com índice de uso eficiente da terra em torno de $19 \%$ e taxa de retorno de $\mathrm{R} \$ 3,00$.

No cultivo consorciado estabelecido com a semeadura do rabanete, no mesmo dia do transplante da alface, Cecílio Filho \& May (2002) obtiveram receita líquida de $\mathrm{R} \$ 26.660,55 /$ ha, enquanto obteve-se $\mathrm{R} \$ 18.036,29 /$ ha, na monocultura da alface, e média de $\mathrm{R} \$ 10.371,00 /$ ha, na monocultura do rabanete.

Avaliando-se a viabilidade agroeconômica de sistemas consorciados em faixas, provenientes de dois grupos (americana e lisa) sendo quatro cultivares de alface cada, com duas cultivares de cenoura, Oliveira et al. (2003) verificaram que nos sistemas consorciados ocorreram melhores aproveitamentos dos recursos ambientais (água, luz e nutrientes), comparativamente ao sistema solteiro. Esse uso mais eficiente da terra variou de $45 \%$ a $116 \%$, no entanto, essas vantagens agronômicas foram confirmadas por indicadores econômicos em algumas das combinações (alface 'Lucy Brown' consorciada com cenoura 'Alvorada' e 'Maravilha das Quatro Estações' consorciada com 'Brasília').

Heredia et al. (2003) observaram que o consórcio da cebolinha e salsa foi melhor, por ter proporcionado incrementos monetários de $25,06 \%$ e 74,93\%, em relação às receitas líquidas da cebolinha e da salsa em cultivo solteiro, respectivamente.
No cultivo consorciado realizado com três grupos de alface (crespa, americana e lisa) e rúcula, em duas épocas de cultivo, Costa et al. (2004) verificaram que as maiores receitas líquidas foram constatadas em consórcios estabelecidos até 7 dias após o transplante (DAT) da alface. No outono-inverno, o consórcio proporcionou aumento de $25 \%$ e $152 \%$ na receita líquida em relação à monocultura de alface e de rúcula, respectivamente; enquanto na primavera, os incrementos foram de $97 \%$ e $73 \%$.

No consórcio de tomate e alface, em duas épocas de cultivo, Rezende et al. (2005a), verificaram que o cultivo consorciado apresentou maiores eficiência de uso da área $(1,92)$ e rentabilidade, quando as duas culturas foram transplantadas na mesma época. No entanto, a maior rentabilidade foi pequena em valores monetários ( $\mathrm{R} \$ 76,81$ / $625 \mathrm{~m}^{2}$ ) e atribuíram o ocorrido ao baixo valor da alface e, conseqüentemente, à sua menor participação na composição da receita do cultivo consorciado.

Diante do exposto, percebe-se que a rentabilidade do cultivo consorciado nem sempre ratifica a grande vantagem agronômica (produtividade) obtida, devendo, portanto, ser fundamental na avaliação da consorciação de culturas. O objetivo desse trabalho foi determinar os custos de produção e avaliar as rentabilidades das monoculturas de alface, rabanete, rúcula, repolho, e em consórcio com pimentão.

As informações sobre as produtividades e os coeficientes técnicos para a cultura de alface, repolho, rúcula e rabanete, em monocultura e em consorciação, foram obtidas em experimento realizado por Rezende et al. (2005b), no período de setembro/2003 a janeiro/2004, na UNESP, Campus de Jaboticabal, SP.

O experimento foi instalado em um LATOSSOLO VERMELHO Eutroférrico típico de textura muito argilosa, A moderado caulinítico-oxídico (EMBRAPA, 1999), com 5,8 de $\mathrm{pH}\left(\mathrm{CaCl}_{2}\right) ; 31 \mathrm{~g} \mathrm{dm}^{-3}$ de matéria orgânica, $124 \mathrm{mg} \mathrm{dm}^{-3}$ de $\mathrm{P}$ (resina). Observou-se, em mmol $\mathrm{dm}^{-3}, 11,5 ; 57 \mathrm{e} 14 \mathrm{de}$ $\mathrm{K}$, de $\mathrm{Ca}$, de $\mathrm{Mg}$ e V\% de 77. Com base na análise de solo, não foram realizadas a calagem e adubação de plantio. A adubação de cobertura foi realizada separadamente para cada cultura, baseando-se na recomendação de Raij et al. (1997).

Para o repolho (Brassica oleracea var. capitata) utilizou-se o híbrido Kenzan, e as cultivares Vera, Cultivada e Crimson Gigante, respectivamente, para alface (Lactuca sativa), rúcula (Eruca sativa) e rabanete (Raphanus sativus). O espaçamento adotado para o repolho, em fileiras duplas no canteiro, foi de $0,80 \times 0,30 \mathrm{~m}$, e de $0,25 \times 0,25 \mathrm{~m}$ para alface, $0,25 \times 0,05 \mathrm{~m}$ para rúcula e $0,25 \times 0,05 \mathrm{~m}$ para 0 rabanete. Essas duas últimas, semeadas diretamente no 
canteiro, foram desbastadas aos 8 dias após a semeadura. As colheitas da alface e repolho foram realizadas, respectivamente, aos 68 e 101 dias e a rúcula e o rabanete aos 31 dias após a semeadura.

A estrutura do custo de produção utilizada foi a do custo operacional de produção, proposta por Matsunaga et al. (1976) e usado pelo Instituto de Economia Agricola IEA. Essa estrutura de custo de produção leva em consideração os desembolsos efetivos realizados pelo produtor durante o ciclo produtivo englobando despesas com mão-de-obra, reparos e manutenção de máquinas, implementos e benfeitorias específicas, operações de máquinas e implementos, insumos e, ainda, o valor da depreciação de máquinas, implementos e benfeitorias específicas utilizados no processo produtivo.

Os coeficientes técnicos referentes às operações de preparo do solo (aração e gradagem) e aplicação de herbicida foram baseados em Brancalião (1999). Os demais coeficientes técnicos foram obtidos durante o experimento, realizado por Rezende et al. (2005b).

Os valores dos itens do custo operacional total (COT), tais como o custo de mão-de-obra, custo hora e depreciação de máquinas e de implemento (trator $72 \mathrm{cv}$, arado 3 discos de 26", grade de 28 disco de 18 ", rotoencanteirador de 6 enxadas, pulverizador com barra de 6001 , carreta de 2 toneladas, motobomba de $20 \mathrm{cv}$, pulverizador costal de 201 , carrinho de mão e bandejas de polipropileno de 128 e 288 células), e de insumos são referentes ao mês de março de 2005, obtidos na região de Jaboticabal, SP.

O custo de mão-de-obra foi calculado a partir do valor do salário mensal obtido junto ao Sindicato dos Trabalhadores Rurais de Jaboticabal, de $\mathrm{R} \$ 335,00$, para mão-de-obra comum, de $\mathrm{R} \$ 424,24$ para o tratorista, para uma carga horária de trabalho de 220 horas por mês, mais encargos sociais assumidos pelo empregador, que equivalem a $42 \%$ do valor do salário.

No custo horário da máquina (CHM) e de implementos (CHI) foram considerados os gastos efetuados com combustível, mais um valor estimado para reparos, manutenção, garagem e uma taxa de seguro. Para o cálculo do de graxa e reparos adotou-se: $\mathrm{CHM}=\mathrm{s}+\mathrm{g}+\mathrm{r}+\mathrm{m}+\mathrm{c}$ e $\mathrm{CHI}=\mathrm{r}+\mathrm{gr}$, onde: $\mathrm{s}=\operatorname{seguro}(0,75 \%$ ao ano do valor $\mathrm{da}$ máquina); $\mathrm{g}=$ garagem ( $1 \%$ ao ano do valor da máquina); $\mathrm{r}$ = reparos ( $10 \%$ ao ano do valor da máquina ou implemento); $\mathrm{m}=$ manutenção; $\mathrm{c}=$ combustível e gr = graxa. Dessa forma o custo-hora sem depreciação de um trator $75 \mathrm{cv}$ foi de $\mathrm{R} \$ 8,41$.

Os preços dos insumos utilizados na produção foram obtidos na região de Jaboticabal e são referentes ao mês de março de 2005.
A depreciação foi calculada com base no método linear, onde o bem é desvalorizado durante sua vida útil a uma cota constante, conforme a seguinte fórmula: $\mathrm{D}=(\mathrm{Vi}$ - Vf)/N; onde: $\mathrm{D}=$ Depreciação em R \$/ano; Vi = valor inicial (novo); $\mathrm{Vf}=$ valor residual e $\mathrm{N}=$ vida útil (anos). Considerou-se um valor residual para o trator igual a $20 \%$ do valor novo, enquanto que, para os implementos, o valor residual foi considerado igual a zero.

Em virtude da cultura do pimentão ser considerada como a principal, no sistema consorciado os custos relativos à mão-de-obra, máquinas, implementos e insumos comuns às duas culturas tais como limpeza do terreno, aração, levantamento dos canteiros, capinas, adubação de plantio, irrigação e aplicação de defensivos foram computados a essa cultura, pois seriam atividades naturalmente realizadas.

A limpeza do terreno compreendeu apenas a aplicação de herbicida (pulverizador 600 litros) para a eliminação de plantas daninhas. Foram realizadas uma aração e duas gradagens no terreno para ambos os sistemas de cultivo, utilizando-se um arado de 3 discos de 26" e uma grade de 28 discos de 18 ',

O preparo dos canteiros foi realizado com rotoencanteirador, também para o repolho e pimentão, tanto em monocultura, quanto no consórcio, devido ao experimento ocorrer no período chuvoso.

A marcação do local de plantio foi realizada para o transplante das mudas de pimentão, repolho e alface. Para as culturas de rabanete e rúcula, a marcação do local de semeadura foi realizada pelo próprio rotoencanteirador. Deve-se destacar que, para o cultivo consorciado, devido ao maior grau de dificuldade na marcação do local de plantio ou de semeadura, foi acrescido $10 \%$ no tempo gasto em monocultura.

A atividade de formação de mudas constituiu-se das operações de lavagem de bandejas, preparo do substrato Plantmax ${ }^{\circledR}$ HA (umedecimento, seguido de mistura para homogeneizar), enchimento das bandejas e semeadura manual. As mudas de pimentão e repolho foram formadas em bandejas de 128 células e as de alface em bandejas de 288 células.

Foram realizadas capinas manuais. Nas monoculturas de rabanete, rúcula e alface foram realizadas duas capinas e no repolho, três, durante todo o ciclo. Já no cultivo consorciado, para cada cultura, fez-se apenas uma capina.

$\mathrm{Na}$ atividade adubação de cobertura, considerouse a demanda de mão-de-obra para a distribuição dos fertilizantes químicos, separadamente para cada cultura, de acordo com as necessidades durante o ciclo. Para o 
repolho, alface, rabanete e rúcula, foram realizadas três operações, tanto na monocultura como no consórcio. As doses dos fertilizantes obedeceram à recomendação de Raij et al. (1997) para cada cultura.

Realizaram-se aplicações de defensivos (fungicidas e inseticidas) de acordo com a necessidade das culturas, sendo três para alface, rúcula e rabanete e sete para o repolho em monocultura.

O sistema de irrigação utilizado foi o de aspersão fixo, caracterizado por conjunto motobomba de $20 \mathrm{cv}$ de potência, sendo os tubos da linha principal de 6 polegadas de diâmetro e os da linha lateral de 4 polegadas com haste de $0,50 \mathrm{~m}$ e distanciados entre si de $12 \mathrm{~m}$ na linha e de $12 \mathrm{~m}$ nas entrelinhas. $\mathrm{O}$ sistema de irrigação utilizado não dependia de mudança dos tubos na área cultivada e, portanto, na estimativa de mão-de-obra comum foi considerado somente o tempo requerido para ligar e desligar o sistema, além de alguns reparos. Considerou-se um tempo médio de irrigação de 30 minutos por dia, durante todo o ciclo da cultura

$\mathrm{Na}$ atividade pós-colheita foram consideradas a lavagem, classificação e o acondicionamento das hortaliças para a comercialização.

A área efetivamente cultivada em 1 hectare foi de $6.600 \mathrm{~m}^{2}$, relativos à área dos canteiros. Nessa área, as populações de repolho, alface, rúcula e rabanete, nos cultivos solteiros (monoculturas) e consorciados foram, respectivamente de 43.956, 105.600, 528.000 e 528.000 plantas.

Para o cálculo da produtividade ( $\mathrm{kg} / \mathrm{ha}$ ) das culturas em monocultura e em consórcio, foi considerada a população realmente presente naquele sistema de cultivo.

Os preços das hortaliças para o cálculo da receita bruta foram os do setor atacadista, CEAGESP (1998), no mês de março.

Para a alface e rabanete considerou-se a classificação "Especial” da CEAGESP, com preço médio respectivamente de $\mathrm{R} \$ 0,56 / \mathrm{kg}$ e $\mathrm{R} \$ 0,76 / \mathrm{kg}$. Para o repolho e rúcula o preço recebido foi de $\mathrm{R} \$ 0,21$ e $\mathrm{R} \$ 1,36$, por quilograma do produto.

A receita líquida $(\mathrm{RL})$ foi obtida pela diferença entre a receita bruta (RB) e o custo operacional total (COT), por ciclo. Deve-se salientar que da receita líquida não foram deduzidos os custos relativos à comercialização, uma vez que esse é bastante influenciado pela distância do comércio e pelo tipo de embalagem a ser usado.

A taxa de retorno (TR) foi calculada mediante a relação entre a receita bruta e o custo operacional total. $\mathrm{O}$ índice de lucratividade (IL) foi obtido da relação entre a renda líquida $(\mathrm{RL})$ e a renda bruta $(\mathrm{RB})$, expresso em porcentagem.
Nas tabelas 1 e 2 estão apresentados os coeficientes técnicos e os custos de produção para os cultivos solteiros de alface, repolho, rúcula e rabanete e consorciadas com pimentão.

O custo operacional total, no consórcio, da alface, repolho, rúcula e rabanete foram de $\mathrm{R} \$ 3.595,98, \mathrm{R} \$ 3.004,35$, $\mathrm{R} \$ 2.868,68$ e $\mathrm{R} \$ 3.585,78$, respectivamente, por hectare. Por outro lado, em todos os casos, nos cultivos solteiros os custos de implantação estimados, para as mesmas culturas, foram de $\mathrm{R} \$ 4.566,40, \mathrm{R} \$ 4.552,36, \mathrm{R} \$ 3.809,11$ e $\mathrm{R} \$ 4.526,22$, respectivamente.

A maior necessidade de mão-de-obra se deu nas operações de colheita e pós-colheita (lavagem, classificação e acondicionamento) que representou cerca de $57,8 \% ; 53,0 \%$ e $53,8 \%$ da demanda de mão-deobra comum nos cultivos solteiros de alface, rúcula e rabanete, respectivamente, aumentando no consórcio para $67,6 \% ; 61,3 \%$ e $62,0 \%$, para as mesmas. Para o repolho, cuja operação é mais simples pela característica do produto, a necessidade de mão-de-obra foi de apenas $18,2 \%$ e $27,4 \%$ para os cultivos solteiro e o consorciado. Segundo Rezende et al. (2005b), essa baixa utilização de mão-de-obra nas operações de colheita e pós-colheita é devido à colheita ser rápida e não ter a necessidade de limpeza rigorosa da cabeça do repolho. A maior necessidade de mão-de-obra comum necessária nos cultivos consorciados pode ser atribuída às operações realizadas para as duas culturas em consórcio, tais como: operações de estabelecimento (transplante, semeadura e desbaste), adubação de cobertura, capinas, colheita e pós-colheita.

Tanto para o sistema de cultivo solteiro quanto no consórcio, o gasto com insumos foi o que representou maiores impactos no COT, sendo 49,3\%, 60,1\%; 55,3\% e $62,0 \%$ para os cultivos solteiros de alface, repolho, rúcula e rabanete, respectivamente, e $49,6 \% ; 63,0 \% ; 57,2 \%$ e $65,2 \%$ as mesmas culturas em consórcio com pimentão. Entre os insumos, o item que mais onerou o COT do sistema de cultivo consorciado, foi o de fertilizantes, sendo responsável por $66,9 \%$; 44,2\%; 71,2\% e 61,3\% para alface, repolho, rúcula e rabanete, respectivamente. Rezende et al. (2005b) relataram a importância de se escolher fontes de nutrientes com custo mais baixo, sem contudo comprometer a eficiência do aproveitamento pelas culturas.

De acordo com os valores estimados (Tabela 3), houve redução do COT da alface, repolho, rúcula e rabanete na ordem de $21,3 \%, 34,0 \%, 24,7 \%$ e $20,8 \%$, respectivamente, no consórcio, quanto comparados aos respectivos cultivos solteiros. 


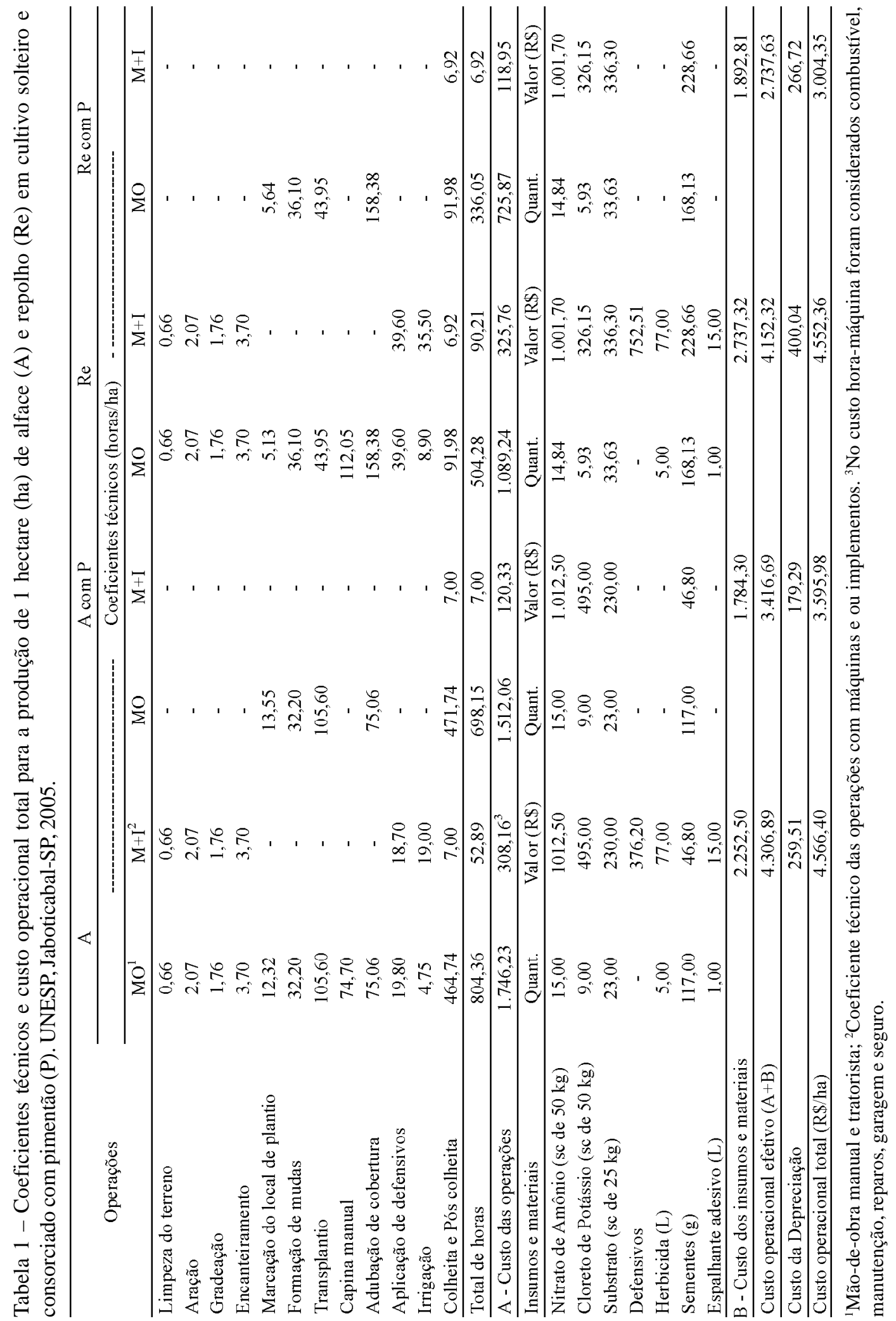




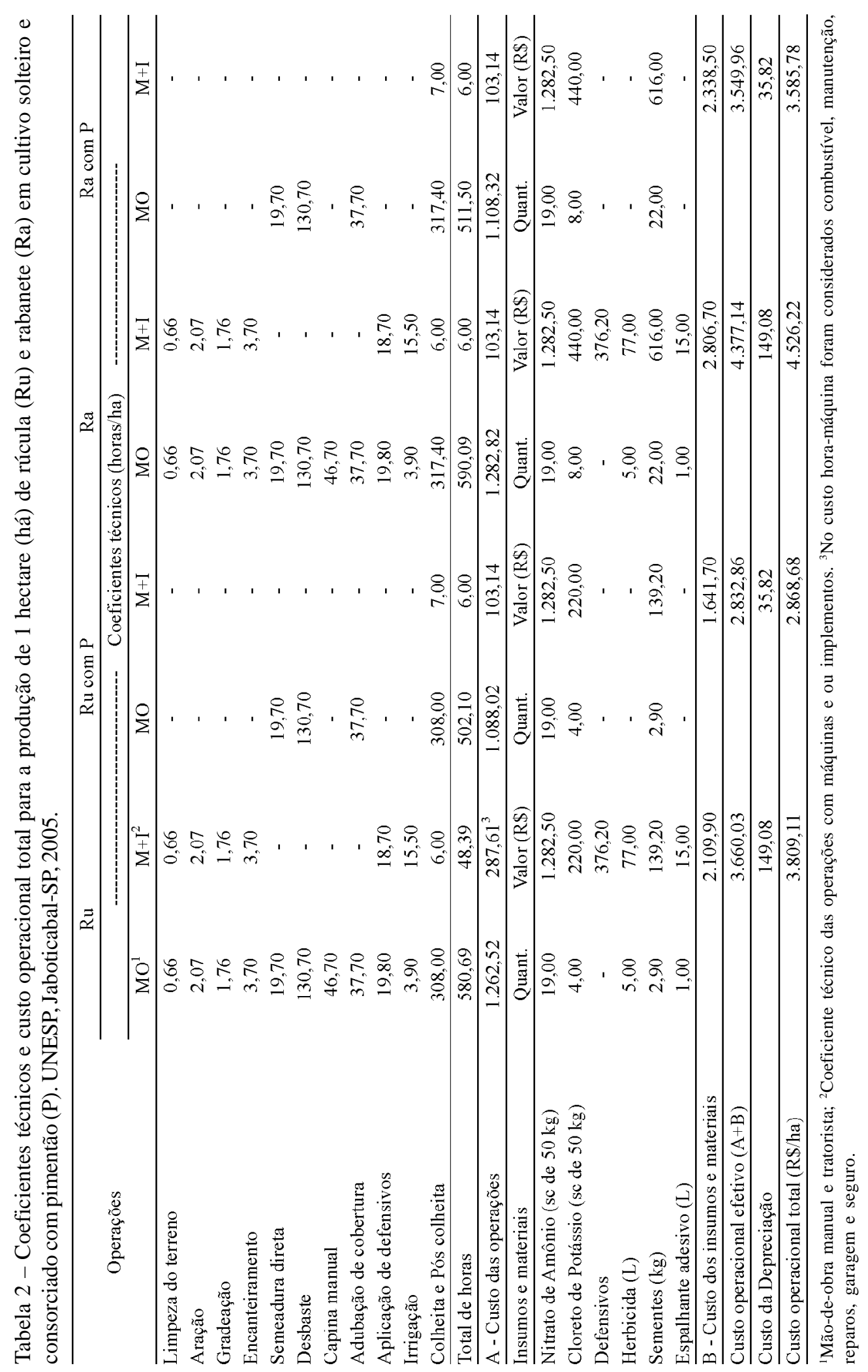

Ciênc. agrotec., Lavras, v. 33, n. 1, p. 305-312, jan./fev., 2009 
Tabela 3 - Produtividade (Prod), custo operacional total (COT), receita bruta (RB), receita líquida (RL), taxa de retorno (TR) e índice de lucratividade (IL) das culturas de repolho, alface, rúcula e rabanete em cultivo solteiro e consorciado com pimentão. UNESP, Jaboticabal-SP, 2005.

\begin{tabular}{|c|c|c|c|c|c|c|}
\hline \multirow{2}{*}{ Sistemas de cultivo } & Prod & COT & RB & RL & \multirow{2}{*}{ TR } & \multirow{2}{*}{$\begin{array}{l}\text { IL } \\
\%\end{array}$} \\
\hline & $\mathrm{kg} / \mathrm{ha}$ & \multicolumn{3}{|c|}{-- } & & \\
\hline Repolho com Pimentão & 74.330 & $3.004,35$ & $40.138,20$ & $37.133,85$ & 13,36 & 92,51 \\
\hline Rúcula com Pimentão & 14.489 & $2.868,68$ & $35.208,27$ & $32.339,59$ & 12,27 & 91,85 \\
\hline Alface com Pimentão & 46.344 & $3.595,98$ & $47.734,32$ & $44.138,34$ & 13,27 & 92,47 \\
\hline Rabanete com Pimentão & 17.908 & $3.585,78$ & $24.713,04$ & $21.127,26$ & 6,89 & 85,49 \\
\hline Solteiro de Repolho & 84.703 & $4.552,36$ & $45.739,62$ & $41.187,26$ & 10,05 & 90,05 \\
\hline Solteiro de Rúcula & 15.151 & $3.809,11$ & $36.816,93$ & $33.007,82$ & 9,67 & 89,65 \\
\hline Solteiro de Alface & 33.077 & $4.566,40$ & $34.069,31$ & $29.502,91$ & 7,46 & 86,60 \\
\hline Solteiro de Rabanete & 16.721 & $4.526,22$ & $23.074,98$ & $18.548,76$ & 5,10 & 80,38 \\
\hline
\end{tabular}

Essa redução no custo de produção dos sistemas consorciados deve-se ao menor número de operações manuais e mecanizadas e redução de insumos, principalmente com defensivos. Isso deve-se às operações que antecedem à implantação das culturas secundárias (alface, repolho, rúcula e rabanete) e que são realizadas e creditadas para a cultura do pimentão (cultura principal do consórcio). Além disso, outras práticas culturais como os tratamentos fitossanitários foram otimizados no sistema consorciado. Também no consórcio, ocorre uma redução de ervas daninhas, pela maior cobertura do solo, que resultou em um menor número de capinas. Esse mesmo comportamento foi observado por Rezende et al. (2005c), quando trabalhando com o consórcio de tomate e alface crespa, verificaram redução do custo de produção do consórcio em 39\%, comparado ao cultivo solteiro de alface.

As maiores receitas bruta e líquida, por hectare, foram observadas nos cultivos consorciados para as culturas de alface ( $\mathrm{R} \$ 47.734,32$ e $\mathrm{R} \$ 44.138,34)$ e repolho ( $\mathrm{R} \$ 40.138,20$ e $\mathrm{R} \$ 37.133,85$ ) (Tabela 3). Porém, quando comparados, aos sistemas solteiros, apenas o cultivo consorciado de pimentão com alface e rabanete apresentaram receita líquida superior que foram de $49,6 \%$ e $13,9 \%$, respectivamente.

A superioridade da rentabilidade desses cultivos consorciados deve ser atribuída à maior produtividade apresentada pela alface $(40,1 \%)$ e rabanete $(7,1 \%)$ em consórcio. Já para o repolho e rúcula, ocorreu redução de $12,3 \%$ e $4,4 \%$, respectivamente, quando consorciados com o pimentão.

Apesar dos sistemas de cultivo consorciados de pimentão com repolho e rúcula não apresentarem receita líquida superiores aos seus respectivos cultivos solteiros, demonstraram ser viáveis agronomicamente. Sua adoção pode ser justificada por outros fatores não valorados nessa análise econômica, tais como conservação do solo e da água, menor impacto ambiental decorrente do menor número de pulverizações com defensivos agrícolas e maior diversidade biológica e de alimentos para o produtor.

As taxas de retorno e índice de lucratividade dos consórcios pimentão com repolho (13,36 e 92,51\%), rúcula $(12,27$ e $91,85 \%)$, alface $(13,27$ e $92,47 \%)$ e rabanete $(6,89$ e $85,49 \%$ ), foram superiores aos seus respectivos cultivos solteiros, sendo as de repolho, rúcula, alface e rabanete, respectivamente, 10,05 e $90,05 \%, 9,67$ e $89,65 \%, 7,46$ e $86,60 \%$ e 5,10 e $80,38 \%$.

Assim, através dos resultados obtidos, pode-se concluir que:

- Os custos operacionais totais das culturas de repolho, rúcula, alface e rabanete, quando consorciadas com pimentão, tiveram redução de $34,0 \%, 24,7 \%, 21,3 \%$ e $20,8 \%$ em relação aos respectivos cultivos solteiros.

- A culturas de alface e rabanete apresentaram aumento na receita líquida em 49,6\% e 13,9\%, respectivamente, quando comparadas aos seus cultivos solteiros.

- A maior rentabilidade foi obtida para alface consorciada com pimentão.

- A taxa de retorno e índice de lucratividade dos consórcios foram superiores aos observados nas monoculturas.

\section{REFERÊNCIAS BIBLIOGRÁFICAS}

ANDRADE, F. V. Valor agroeconômico do consórcio alface e cenoura em dois sistemas de cultivo em faixa. 2002. $81 \mathrm{f}$. Dissertação (Mestrado em Agronomia: Fitotecnia) - Escola Superior de Agricultura de Mossoró, Mossoró, 2002. 
BARROS JÚNIOR, A. P. Densidades populacionais das culturas componentes no desempenho agroeconômico do consórcio cenoura e alface em bicultivo em faixa. 2004. 77 f. Dissertação (Mestrado em Agronomia: Fitotecnia) Escola Superior de Agricultura de Mossoró, Mossoró, 2004.

BEETS, W. C. Multiple: cropping. World Crop Livestock, Amsterdam, v. 29, p. 25-27, 1977.

BRANCALIÃO, S. R. Avaliação econômica dos sistemas de semeadura direta e convencional na sucessão soja/sorgo na região de Ribeirão Preto. 1999. 45 f. Monografia (Graduação) - Universidade Estadual Paulista, Jaboticabal, 1999.

CAMARGO FILHO, W. P. de; MAZZEI, A. R. Mercado de verduras: planejamento e estratégia na comercialização. Informações Econômicas, São Paulo, v. 31, n. 3, p. 45-54, 2001.

CEAGESP. Programa de adesão voluntária, elaborada pelo ministério da agricultura e abastecimento, secretaria de agricultura de São Paulo para classificação do pimentão e alface. São Paulo, 1998. Folheto.

CECILIO FILHO, A. B.; MAY, A. Produtividade das culturas de alface e rabanete em função da época de estabelecimento do consorcio, em relação aos monocultivos. Horticultura Brasileira, Brasília, v. 20, n. 3, p. 501-504, 2002.

COSTA, C. C.; REZENDE, B. L. A.; CECÍLIO FILHO, A. B.; MARTINS, M. I. E. G. Análise econômica de cultivos consorciados de grupos de alface x rúcula, em duas épocas, Jaboticabal-SP. In: CONGRESSO BRASILEIRO DE OLERICULTURA, 21., 2003, Recife. Anais... Recife: SOB, 2003. CD-ROM.

DAVIS, J. H. C.; WOOLLEY, J. N. Genotypic requirement for intercropping. Field Crops Research, Amsterdam, v. 34, n. 3/4, p. 407-430, 1993.

EMPRESA BRASILEIRA DE PESQUISA AGROPECUÁRIA. Sistema brasileiro de classificação de solos. Rio de Janeiro: Embrapa Solos, 1999. 412 p.

FRANCIS, C. H. Distribution and importance of multiple cropping. In: McMillan, 1986. p. 15-19.

HEREDIA, Z. N. A.; VIEIRA, M. C.; WEISMANN, M.; LOURENÇÃO, A. L. F. Produção de cebolinha e de salsa em cultivo solteiro e consorciado. In: CONGRESSO
BRASILEIRO DE OLERICULTURA, 21., 2003, Recife. Anais... Recife: SOB, 2003. CD-ROM.

HORWITH, B. A role for intercropping in modern agriculture. BioScience, Washington, v. 35, n. 4, p. 286291, 1985

MATSUNAGA, M. Metodologia de custo de produção utilizada pelo IEA. Agricultura, São Paulo, v. 1, n. 1, p. 123-140, 1976.

OLIVEIRA, A. M. de; BEZERRA NETO, F.; NEGREIROS, M. Z. de; OLIVEIRA, E. Q. de. Indicadores agroeconômicos de consórcio cenoura e alfaces americanas em dois sistemas de cultivo em faixas. In: CONGRESSO BRASILEIRO DE OLERICULTURA, 21., 2003, Recife. Anais... Recife: SOB, 2003. CD-ROM.

RAIJ, B. van; CANTARELLA, H.; QUAGGIO, J. A.; FURLANI, A. M. C. Recomendações de adubação e calagem para o Estado de São Paulo. Campinas: IAC, 1997. 285 p.

REIS, R. P.; TAKAKI, H. R. C.; REIS, A. J. dos. Como calcular o custo de produção. Lavras: UFLA, 1999. 15 p.

REZENDE, B. L A.; CECÍlIO FILHO, A. B.; CANATO, G. H. D.; MARTINS, M. I. E. G. Análise econômica de consórcios de alface $\mathrm{x}$ tomate, em cultivo protegido, em Jaboticabal (SP). Científica, Jaboticabal, v. 32, n. 1, p. 9-14, 2005 a.

REZENDE, B. L. A.; CECÍLIO FILHO, A. B.; MARTINS, M. I. E. G.; COSTA, C. C.; FELTRIM, A. L. Viabilidade econômica das culturas de pimentão, repolho, alface, rabanete e rúcula em cultivo consorciado. Informações Econômicas, São Paulo, v. 35, n. 3, p. 22-37, 2005 b.

REZENDE, B. L. A.; COSTA, C. C.; CECÍLIO FILHO, A. B.; MARTINS, M. I. E. G. Custo de produção e rentabilidade da alface crespa, em ambiente protegido, em cultivo solteiro e consorciado com tomateiro, Jaboticabal, estado de São Paulo. Informações Econômicas, São Paulo, v. 35, n. 7, p. 42-50, 2005 c.

WILLEY, R. W. In Intercropping: its importance and research needs: part 1: competition and yied advantages. Field Crops Abstract, Wallingford, v. 32, n. 1, p. 1-10, 1979.

ZAFFARONI, E. dos. Yield stability of sole and intercropping systems in the northeast of Brazil. Pesquisa Agropecuária Brasileira, Brasília, v. 22, n. 4, p. 393-399, 1987. 